\title{
Ação afirmativa e raça no Brasil contemporâneo: um debate sobre a redefinição simbólica da nação
}

\author{
Thais Santos Moya \\ Doutoranda em Sociologia (Universidade Federal de São Carlos) \\ São Carlos, Brasil \\ thais_moya@yahoo.com.br \\ Valter Roberto Silvério \\ Doutor em Ciências Sociais (Universidade Estadual de Campinas) \\ Professor da Universidade Federal de São Carlos \\ São Carlos, Brasil \\ silverio@ufscar.br
}

Resumo

0 artigo centra- se sobre a repercussão da ação afirmativa com critério racial na mídia impressa brasileira (revistas V eja, É poca e I stoé e jornais Folha de S. Paulo e E stado de S. Paulo) por meio da análise de enquadramento, durante o período de 1995 a 2006, referente à consolidação da temática no âmbito estatal. A análise enfatiza os enquadramentos interpretativos de "posicionamento", que corresponde às publicações que apresentaram avaliações sobre o sistema de cotas raciais; de "argumentação", que observa as construções argumentativas que sustentaram as referidas avaliações, e de "prognóstico", que explora as propostas alternativas ou complementares ao sistema citado. A principal conclusão refere- se ao recuo das denúncias sobre as desigualdades raciais brasi leiras a partir de 2005, acompanhadas de um intenso aumento de reportagens e artigos desfavoráveis ao avanço da ação afirmativa com critério racial no país.

Palavras-chave: relações raciais; ação afirmativa; Estado; nação; enquadramento midiático.

A S CIÊN CIAS SO CIAIS BR ASILEIR AS sempre se preocuparam com as complexidades do processo de racialização vigente na formação do Estado nacional brasileiro, pois, assim como em outras sociedades que passaram pela experiência da colonização, tal processo resultou em hierarquias estruturantes de cunho simbólico e material que ainda hoje refletem profundas disparidades socioeconômicas entre as populações branca e negra do país.

0 equacionamento dessas disparidades pauta a agenda nacional há mais de uma década, entretanto, a definição de qual perspectiva teórica deve conduzir as políticas que promovam as soluções al mejadas parece estar longe de um consenso nacional.

0 embate configura-se principal mente a partir de duas perspectivas distintas. De um lado, estão aqueles que compreendem tais mazelas sociais por uma perspectiva predominantemente econômica, desconsiderando total ou parcialmente as intersecções entre o 'ser pobre' e o 'ser negro' (Silvério, 2004, p. 65). 0 prognóstico político decorrente dessa concepção baseia- se em políticas de cunho universalista, que, quando muito consideram apenas um recorte de pobreza para políticas mais 
específicas. De outro lado, encontram-se aqueles que entendem tais desigualdades como resultado de um processo de racialização que configurou e consolidou socialmente uma parcela da população como "outra" (ou não branca) e a alocou em uma posição social de desprestígio, a qual suspendeu a sua humanidade, racionalidade e sua estética e colocou sua subjetividade em descrédito. As propostas políticas decorrentes dessa perspectiva compreendem a raça ${ }^{1}$ como uma categoria de inteligibilidade desse processo, portanto, é considerada essencial para o combate das desigualdades materiais e simbólicas oriundas dele (G uimarães, 2003, p. 96).

Esse dissenso foi evidentemente acentuado com as recentes propostas e implementações de cotas raciais. 0 acirramento do debate, 0 qual tem sido registrado e veiculado pelos meios de comunicação do país, não se deve apenas pelo caráter particularista da ação afirmativa, mas, sobretudo, pelo uso do critério racial em suas formulações. D esse modo, este artigo instrumentalizou a mídia impressa, ${ }^{2}$ por meio da análise de enquadramento, ${ }^{3}$ como um foco privilegiado sobre 0 debate nacional em torno das ações afirmativas com critério racial, com vistas a compreender e caracterizar quais são as principais interpretações que orientam tal disputa política.

\section{O debate na mídia impressa: posicionamento, argumentos e prognósticos acerca das cotas raciais 4}

A análise do referido debate veiculado nos principais jornais e revistas do país - Folha de $S$. Paulo, 0 E stado de S. Paulo, V eja, I stoÉ e É poca - demonstrou que, dentre as publicações que expuseram um enqua- dramento interpretativo sobre as cotas raciais, ou seja, ajuizaram um posicionamento sobre elas, evidenciouse uma atitude de contrariedade majoritária em todas as mídias citadas. Com ênfase para a revista $V$ eja e 0 jornal 0 E stado de $S$. Paulo, que registraram uma contrariedade ao si stema de cotas raciais próxima aos 75\% dos seus enquadramentos inter pretativos.

\begin{tabular}{|c|c|c|c|c|}
\hline \multirow{2}{*}{ Mídia } & \multicolumn{3}{|c|}{ Posicionamento } & \multirow{2}{*}{ Tota } \\
\hline & Favorável & Contrário & Não evidente & \\
\hline ISTOÉ & $\begin{array}{c}8 \\
(42,1 \%)\end{array}$ & $\begin{array}{c}11 \\
(57,9 \%)\end{array}$ & - & 19 \\
\hline ÉPOCA & $\begin{array}{c}10 \\
(34,5 \%)\end{array}$ & $\begin{array}{c}17 \\
(58,6 \%)\end{array}$ & $\begin{array}{c}2 \\
(6,9 \%)\end{array}$ & 29 \\
\hline VEJA & $\begin{array}{c}6 \\
(9,8 \%)\end{array}$ & $\begin{array}{c}46 \\
(75,5 \%)\end{array}$ & $\begin{array}{c}9 \\
(14,7 \%)\end{array}$ & 61 \\
\hline ESTADO & $\begin{array}{c}15 \\
(21,4 \%)\end{array}$ & $\begin{array}{c}51 \\
(72,9 \%)\end{array}$ & $\begin{array}{c}4 \\
(5,7 \%)\end{array}$ & 70 \\
\hline FOLHA & $\begin{array}{c}127 \\
(38,3 \%)\end{array}$ & $\begin{array}{c}178 \\
(53,6 \%)\end{array}$ & $\begin{array}{c}27 \\
(8,1 \%)\end{array}$ & 332 \\
\hline Total & $\begin{array}{c}176 \\
(34,4 \%)\end{array}$ & $\begin{array}{c}303 \\
(59,4 \%)\end{array}$ & $\begin{array}{c}42 \\
(8,2 \%)\end{array}$ & 511 \\
\hline
\end{tabular}

O s principais argumentos para a posição de contrariedade às cotas raciais presentes no material analisado puderam ser caracterizados em três enquadramentos destacados a seguir.

0 enquadramento argumentativo contrário mais acionado afirma que 0 sistema de cotas desrespeita 0 mérito individual e, portanto, infringe o princípio constitucional da isonomia. Essa argumentação entende que o mérito é o único instrumento que garante igualdade entre as pessoas nos processos seletivos, pois trata os indivíduos sem distinção, avaliando exclusivamente a competência de cada um. Perante isto, as co-

1 Embora tenha sua gênese nas Ciências Biológicas, o conceito "raça" é interpretado e utilizado nas Ciências Sociais como um construto social que orienta e ordena a dinâmica e o discurso da vida social. Ver Guimarães, 2005[1999], Stepan, 1994, Costa, 2002.

2 A análise aqui apresentada compreende as revistas Veja, IstoÉ e Época e os jornais O Estado de S. Paulo e Folha de S. Paulo, durante o período de 1995 a 2006, referente aos governos FHC (1995-2002) e Lula (2003-2006), entendidos como marcos da oficialização da temática antirracista no âmbito estatal. O procedimento de coleta das reportagens foi efetuado por meio dos sistemas de busca dos sites oficiais (Internet) dos respectivos veículos de comunicação, que foram acionados com as palavras-chaves 'negros e cotas'. No total, foram 934 publicações analisadas, sendo 780 dos jornais e 154 das revistas.

3 "Enquadramentos são princípios de seleção, ênfase e apresentação compostos de pequenas teorias tácitas sobre o que existe, o que acontece e o que é importante. [...] Enquadramentos midiáticos são padrões persistentes de cognição, interpretação e apresentação, de seleção, ênfase e exclusão, através dos quais os detentores de símbolos organizam de forma rotineira o discurso, seja verbal ou visual." (Giltlin, 1980:6-7. In: Leal, 2007, p. 4).

4 Seguindo as orientações de Porto (2001), os enquadramentos interpretativos empregados neste artigo serão os enquadramentos de avaliação moral, causas e soluções (Porto, 2001, p. 13). O enquadramento de avaliação moral será nomeado nesta pesquisa de Posicionamento e tratará das reportagens que apresentam avaliações (favoráveis ou contrárias) sobre o sistema de cotas raciais. O enquadramento de causas será chamado de Argumentativo e abrange os argumentos noticiados que sustentam o posicionamento favorável ou contrário ao sistema de cotas raciais. 0 enquadramento de soluções, que aqui será denominado prognóstico (Scheufele,1999), será utilizado para referir-se às notícias que apresentam soluções divergentes ou medidas complementares ao sistema de cotas raciais. 
tas, na medida em que reivindicam critérios coletivos e não individuais, são negativamente compreendidas como uma "discriminação às avessas".

A justificativa que define o sistema de cotas como uma medida racial ista que oficial iza o racismo institucional e acirra os conflitos raciais privados foi o segundo argumento mais recorrente. Esse enquadramento está fortemente fundamentado na concepção de que no Brasil, as relações sociais não são racializadas devido ao seu alto nível de miscigenação. Portanto, 0 sistema de cotas é entendido como uma política imperativa que obriga a classificação racial de uma população que não se define e relaciona racialmente, ou seja, para tal argumentação as cotas raciais tencionam transformar a nacionalidade brasileira, compreendida como beneficamente mestiça, em um sistema bipolarizado entre negros e brancos.

Esse enquadramento que expõe o sistema de cotas como uma medida que racializa a sociedade, institucionalizando o "racismo brasileiro", juntamente com 0 argumento citado anteriormente que julga as cotas inconstitucionais por desrespeitar o mérito individual foram os argumentos contrários mais frequentes da revista $V$ eja. Entretanto, é necessário um destaque na temporalidade destas duas argumentações, pois há uma evidente inversão na frequência e visibilidade delas. N o biênio 2002/2003, período de aprovação e implantação dos primeiros sistemas de cotas para negros no país, o argumento mais acionado é o que aponta uma possível inconstitucional idade dos sistemas. Já em $2006^{5}$ há uma nítida ascensão do argumento de que as cotas oficializam um racismo institucional.

0 terceiro enquadramento argumentativo mais recorrente e contrário às cotas raciais culpa a falta de qualidade das escolas públicas como responsável pela baixa aprovação dos negros e pobres nos vestibulares das universidades. Segundo esse argumento, estudantes de escola pública competem desigualmente com alunos das escolas privadas e por isso não ingressam na universidade. Portanto, é necessário melhorar o ensino básico público para que seus alunos ingressem nas universidades pelo seu próprio mérito, o que preserva a isonomia do indivíduo e exclui o critério racial do diagnóstico. Para esse argumento, as cotas são vistas como um subterfúgio político, com baixo custo, para não melhorar o sistema educacional público, este visto como principal problema a ser sanado para que a população negra e pobre "naturalmente" adentre no ensino superior.

O posicionamento favorável ao sistema de cotas raciais presente nas mídias analisadas pôde ser caracterizado em quatro enquadramentos argumentativos principais.
0 argumento mais acionado para a defesa do sistema de cotas foi aquele que 0 apresenta como promotor de justiça social, por meio da inclusão da população negra, a mais economicamente carente, em locais de poder e prestígio social que Ihes permitam ascensão econômica e mel horia da qualidade de vida. Tal ação diminuiria, assim, as injustiças presentes em nossa sociedade.

O segundo enquadramento argumentativo favorável mais frequente define o sistema de cotas como uma política de reparação histórica destinada à população afro-descendente, em razão não só do passado escravocrata brasileiro, mas também pelas décadas de negligência política no combate ao racismo e na promoção da inclusão dos negros na sociedade.

U $\mathrm{m}$ terceiro enquadramento recorrente na defesa das cotas raciais entende que estas geram uma polêmica positiva, a qual tem impulsionado debates nacionais que extrapolam a questão do racismo e suas práticas, abordando, por exemplo, a qualidade do sistema educacional brasileiro, a condição de trabalho e formação dos professores, a pertinência do conteúdo ensinado, a eficiência e pertinência do vestibular etc. Portanto, essa capacidade de mobilizar discussões políticas em torno de questões nacionais também foi usada como argumento positivo às cotas.

Por fim, um enquadramento argumentativo favorável às cotas raciais pouco recorrente nas mídias analisadas, mas não menos importante, refere-se à defesa do reconhecimento e da valorização da diversidade racial brasileira em contrapartida ao modelo eurocêntrico vigente e dominante nos locais de poder.

A análise do enquadramento de prognósticos é fundamental porque discute as proposições políticas em voga nos meios de comunicação que visam equacionar as desigualdades racialmente orientadas. $\mathrm{N} 0$ entanto, quase metade do material analisado não apresentou nenhum tipo de prognóstico, postura recorrente inclusive nas publicações contrárias ao sistema de cotas raciais. 0 que demonstra que existe uma parcela considerável da oposição às cotas raciais que não almeja mudanças em nossas relações hierárquicas estruturantes ou, ao menos, nada propõe para que sejam alteradas.

0 prognóstico apresentado com maior frequência nos jornais e nas revistas refere-se à reivindicação de investimentos universais que visem melhorar o ensino básico público para que, assim, haja possibilidade de uma concorrência efetiva entre estudantes egressos das escolas públicas e privadas. Consolidar-se-ia, portanto, o "projeto moderno" da igualdade material entre os indivíduos, garantida pelo Estado, a qual possibilita uma disputa por meio apenas do esforço e do desempenho individual, regida pelas leis do merca-

5 Ressalta-se que, durante o ano de 2006, o PL 6264/ 05, que prevê o Estatuto da Igualdade Racial, foi aprovado no Senado e encaminhado à Câmara, o primeiro manifesto contrário aos projetos de lei que requerem cotas foi entregue ao Congresso e o livro Não somos racistas (Kamel, 2006) foi publicado e amplamente divulgado pelos meios de comunicação. 
do. Entretanto, essa percepção da realidade social não compreende que as diferenças social mente construídas (como gênero, raça, regionalidade, sexualidade etc.) estabelecem e reproduzem desigualdades entre os indivíduos. $\mathrm{O}$ u seja, entendem stricto sensu a concepção de indivíduo, sem qualquer distinção ou diferenciação, a qual, no plano ideal em que os direitos fundamentais são garantidos, redundaria em um cidadão.

Tal proposta, quando colocada como alternativa oposta ao sistema de cotas raciais, fundamenta- se, primeiramente, na preservação do mérito como valor hegemônico de orientação das disputas individuais e na negação da questão racial como fator discriminatório presente nas relações de poder vinculadas, principalmente, ao sistema educacional. Portanto, além de situarem as cotas raciais como violadoras do tratamento igualitário mediado pelo mérito, também as posicionam como subterfúgios paliativos e de bai xo custo que concorrem com a melhoria concreta do ensino público brasileiro.

Essa ideia de que há uma concorrência entre a ação afirmativa no ensino superior e 0 incremento do ensino básico ignora que uma alternativa não exclui a outra e que, pelo contrário, são perfeitamente convergentes. Porém, a ideia dessa falsa disputa está fortemente difundida no país, como demonstraram os meios de comunicação analisados, o que ratifica que a discussão em torno da ação afirmativa traz consigo possibilidades de transformações educacionais profundas e que repercutem diretamente na redefinição si mbólica de nossos fundamentos nacionais.

D emarcações relevantes estão em jogo nesse debate. A democratização do ensino superior público não é um consenso, pelo contrário, há uma parcela significativa de pensadores e acadêmicos que afirmam que a universidade pública não deve se preocupar com tal questão. Por essa concepção, o seu foco deve ser exclusivamente a excelência acadêmica, fundamentada apenas na competência individual, ou seja, na universidade só devem estar as pessoas mais preparados. Segundo tais perspectivas, a universidade pública é (e deve continuar sendo) o local máximo e restrito da produção do saber e, consequentemente, do poder.

O reitor da U niversidade Estadual Paulista (U nesp), Antônio $M$ anoel dos Santos Silva, classificou as duas propostas de populistas. Para Silva, a inclusão social dos mais pobres não é função apenas da universidade. "Ela é o local de uma elite, que não a financeira: a dos que podem ser aproveitados pela nação para desenvolver a pesquisa, estar na liderança do País", disse. "Se houvesse uma política educacional, a inclusão já estaria sendo feita antes, no ensino médio." (E stado de S. Paulo, $\mathrm{N}$ acional, 7/12/2002 - grifo nosso)

0 tema da "indusão social" passou a ser dominante no debate intelectual sobre o ensino superior do país, e isto está prejudicando a discussão de outros temas fundamentais. U ma forte pressão "igualitarista" também está afetando instituições que deveriam ter como base os valores tradicionais da academia: competência, competição e concentração de talentos, de uma "elite" do conhedimento. Estas foram al gumas das afirmações feitas ontem no primeiro debate de uma importante série de seminários que começaram agora na U SP, por iniciativa do seu Instituto de Estudos A vançados (IEA). [...] N os últimos anos tomou conta das universidades o tema da "inclusão", isto é, de políticas capazes de fazer com que grupos menos representados tenham acesso ao ensino superior - como alunos vindos do ensino público, de baixa renda ou mesmo de "raças", caso das cotas para negros. U m dos temas que Schwartzman considera excluído pela concentração do debate na "inclusão" é a necessidade de um país ter universidades de classe internacional. " $U \mathrm{~m}$ país precisa de instituiçoes que tenham concentração de talentos, sólidas, com competência em recursos humanos capaz es de dialogar e entender o que se passa no resto do mundo", afirma Schwartzman. (F olha de S. Paulo, 10/11/2004 - grifo nosso)

\section{Brancos e ricos predominam nos cursos mais}

disputados - 0 perfil do aluno da U SP depende do endereço. [...] 0 que os alunos mais têm de homogêneo é a cor: $80 \%$ deles são brancos. 0 s negros (pretos e pardos), que representam $45 \%$ da população brasileira segundo o C enso de 2000, não chegam a $10 \%$ dos uspianos (9,8\%). [...] "A U SP tem todo interesse em ficar mais próxima da cor básica da sociedade brasileira, mas não podemos descuidar da função social da universidade, que é a de formar pessoas muito bem preparadas, lideranças das próximas gerações. $\mathrm{N}$ ão podemos, em hipótese alguma, diminuir as exigências para o ingresso", afirma Sonia Teresinha de Sousa Penin, pró-reitora de graduação. A mesma opinião é compartil hada pelo reitor, A dolpho José M elfi. "N ão vejo com simpatia o sistema de cotas para negros. A cho que estaremos discriminando-os de uma maneira muito mais séria. [V ai parecer que] qual quer negro que está na universidade entrou por cota." Segundo ele, serão discutidos a partir de março modelos de sistemas de cotas que poderão ser implantados na universidade. Porém o reitor adianta que deverá ser priorizado 0 aspecto socioeconômico dos alunos e não a etnia. A lém do aspecto da cor, a U SP corre o risco de se tornar homogênea também em relação à procedência dos seus alunos: $70 \%$ dos que ingressaram no ano passado vieram de escola particular. [...] N a opinião de M elfi, esse não é um problema da U SP, mas sim dos governos federal, estadual e municipal. "T emos é que melhorar o nível do nosso ensino fundamental e médio. A U SP está colaborando para isso na formação e capacitação de professores." [...] Setenta anos após sua fundação, a U SP ainda não conhece de fato os seus alunos. As únicas informações globais existentes (socioeconômicas) são fornecidas pela Fuvest a partir dos dados dos inscritos no vestibular. $\mathrm{N}$ ão há um estudo abrangente 
dos alunos após o ingresso na universidade. (F olha de S. Paulo, 23/1/2004 - grifo nosso)

Tal concepção acerca da "função social" das universidades públicas foi reiterada por dois editoriais da Folha:

O utra novidade [do Índice de Desenvolvimento do Ensino Superior/ $M E C$ ], mais polêmica, fica por conta do "comprometimento social da instituição". A idéia aqui é premiar faculdades que tenham maior envolvimento com a "comunidade". O s avaliadores deverão considerar itens como cotas para negros, ensino à distância, preocupação em dar resposta a problemas nacionais e regionais etc. São critérios que, a título de revestir a avaliação de caráter "politicamente correto", parecem propensos a demagogias e desvios. É claro que é importantíssimo formar, por exemplo, engenheiros capacitados para resolver problemas de transporte público. M as o paístambém precisa de profissionais aptos a projetar aviões e foguetes. Será que pela lógica educacional petista a universidade que forma o segundo tipo de engenheiro deve ser "punida" ? (Folha de S. Paulo, Editorial, 7/12/2003)

0 mérito caracteriza a universidade. Da instituição deve participar, seja como aluno, seja como mestre, apenas quem, sob critérios públicos e objetivos, demonstre domínio sobre uma área do saber. $\mathrm{N}$ ão basta ao candidato conhecer o mínimo, como defensores da reserva de vagas apregoam. É preciso que sobressaia na disputa com outros competidores. N essa seleção, atributos de origem social não deveriam ser levados em conta, pois redundam em relativizar a excelência. A sociedade precisa decidir se quer mesmo optar por fazer justiça social combatendo os efeitos de um problema, e não as suas causas. Esta F ol ha entende que a universidade não é local adequado para tal experimentalismo. De todo modo, é preciso ter em mente que a opção pelas cotas não se faz sem custos. E o custo é prejudicar o futuro do ensino e da pesquisa de ponta no Brasil. (F olha de S. Paulo, Editorial, $7 / 10 / 2006)$

A aplicação de outras modalidades de ação afirmativa, além das cotas, foi o segundo prognóstico mais presente entre as publicações analisadas. Embora esse prognóstico possa apontar uma alternativa que permita a ampliação da ação afi rmativa, parece que ele tem sido usado apenas como uma dissimulação que ameniza e oculta a real contrariedade ao sistema de cotas, pois foram poucos os apontamentos específicos de outras modalidades da política afirmativa. Seguem as que foram citadas em ordem decrescente de destaque: 1ํ) curso pré-vestibular para negros e carentes; 2ㅇ) sistemas de bônus adicionais nos processos seletivos das universidades, como os vigentes na U nicamp e na U SP; 3) bolsas de estudo para negros e carentes; 40) políticas que garantam a permanência dos estudantes cotistas, e 5o) cotas para docentes.

0 terceiro prognóstico mais recorrente sugere cotas com critério econômico ou para estudantes oriundos de escola pública ao invés do critério racial. Trata-se de uma alternativa oriunda de dois raciocínios diferentes, mas convergentes. U m raciocínio advém da concepção de que as desigualdades entre brancos e negros são resultantes apenas das diferenças econômicas, portanto, não consideram o vetor racial e em última instância consideram apenas a existência de pobres, ignorando o critério racial, que é visto como ineficaz, pois só o critério econômico corrigiria a verdadeira distorção. 0 outro raciocínio leva em conta 0 vetor racial da desigualdade advinda da discriminação, mas o encara como ameno e circunscrito a um nível privado em razão das especificidades das relações intrinsecamente mestiças da sociedade. Portanto, repudia a política afirmativa com critério racial, por considerar que esta institucionalizaria o racismo e ampliaria seu escopo e sua intensidade de atuação. Para essa concepção, as cotas com critérios econômicos seriam uma alternativa de inclusão e promoção da igualdade sem racialização da sociedade.

\section{Inflexões em torno do racismo brasileiro}

A análise realizada sobre o debate brasilei ro acerca da ação afirmativa com critério racial demonstrou que, entre os anos de 1995 a 2004, foi observado um reconhecimento midiático, por parte das revistas e dos jornais, de que as disparidades sociais brasileiras têm uma causalidade na questão racial, ou melhor, no racismo. Essa atitude colocou em xeque o ideário da democracia racial brasileira, que correspondia a um dos códigos maiores do sentido dominante de nossa nacionalidade, entendida como assimilacionista, não segregacionista e, portanto, não racista.

Durante esse período, por exemplo, a revista I stoÉ estampou duas vezes em sua capa o tema do racismo brasileiro. A primeira capa, publicada em 1996, anunciou em letras garrafais " 0 fim do mito", referindo-se à democracia racial, como o seguinte subtítulo: "0 Brasil racista: Pesquisa exclusiva IST O É / Brasmarket mostra que os brasileiros assumem o preconceito racial e derrubam a tese da convivência pacífica entre negros e brancos" (IstoÉ , Ed. 1405, 1996).

A outra capa, publicada em 2001, questionou seus leitores com a seguinte pergunta: "Você é racista?", e afirmou que, embora a sociedade prefira ignorar a existência do racismo, ele vigora com diversas facetas e práticas. Vale ressaltar que ambas as edições apresen- 
Gráfico 1 - Frequência anual das publicações das revistas e jornais

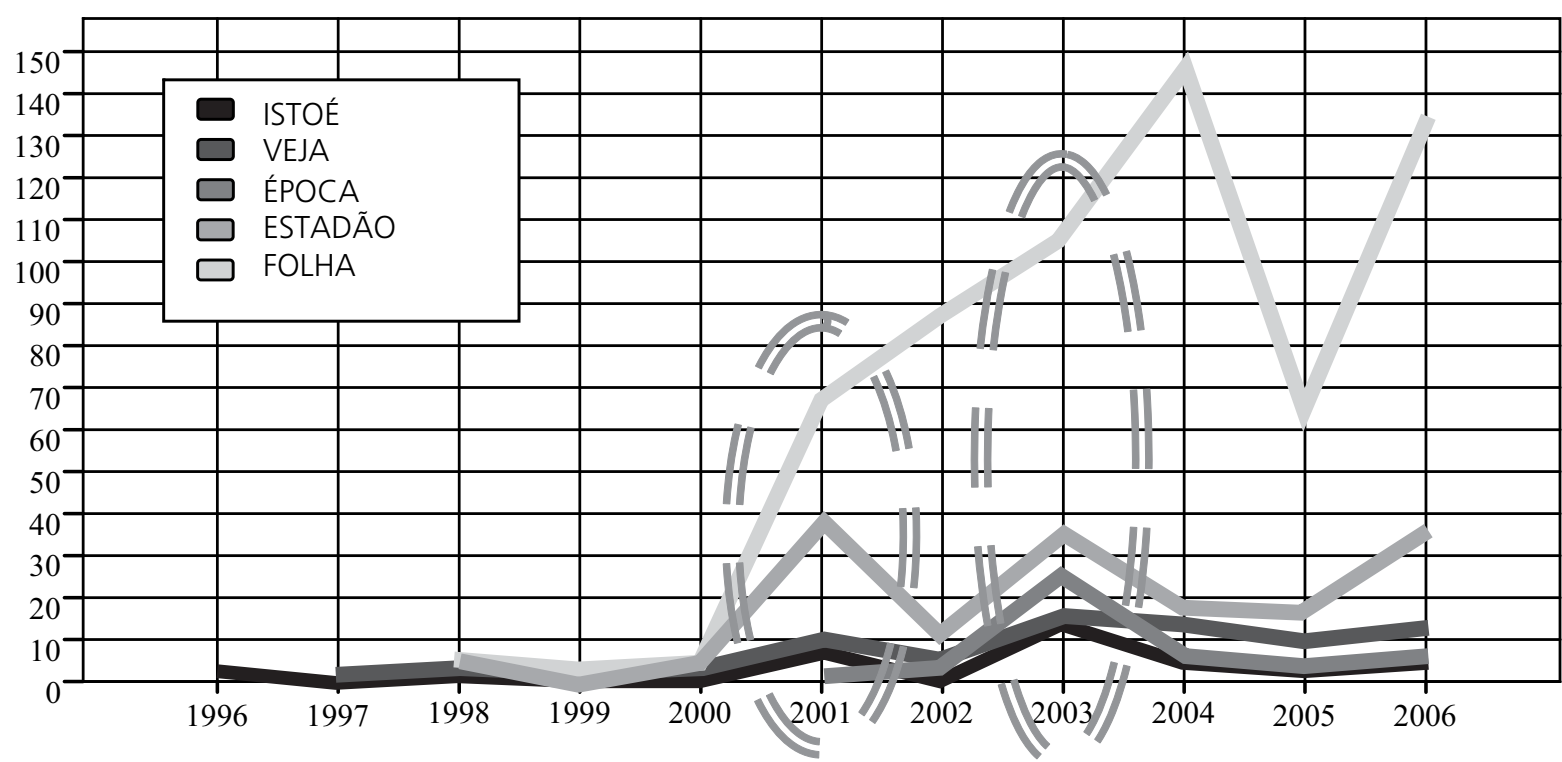

taram no seu interior reportagens que denunciavam o racismo brasileiro, além de um editorial que tratou do tema.

O Brasil sofre de um intenso e silencioso racismo, especialmente contra o negro. 0 mito da democracia racial começa a cair por terra. (I stoÉ , ed. 1405, 1996 - 0 fim do mito)

O B rasil se orgulha, aqui e lá fora, de praticar a autêntica democracia racial. Pega bem, mas não é verdade. A tal convivência harmoniosa entre brancos e negros é pura miragem diante da realidade estatística. (I stoÉ, ed. 1672, 2001 - Título: Igualdade racial é blefe)

Esse processo de reconhecimento e denúncia do racismo brasileiro pela mídia deve ser entendido a partir de um conjunto de fatores complementares daquele período, a saber: 1) a publicação dos resultados de pesquisas sobre as desigualdades raciais no país, produzidas por institutos renomados como o IBGE e o IPEA, que apontaram uma intensa dessemelhança em entre as condições de vida dos brancos e negros; 2 ) a pressão denunciativa do movimento social negro 6 no processo de desmascaramento da democracia racial, fortemente representada na M archa Z umbi dos Palmares em Braślia no ano de 1995; 3) o compromisso do governo federal (FHC) de combate ao racismo e de promoção da igualdade racial, que se fortaleceu durante o período de preparação para a III C onferência $M$ undial de Combate ao R acismo, D iscriminação $R$ acial, X enofobia e Intolerância Correlata, promovida pela O N U em 2001, e 4) a influência dos debates e acordos advindos dessa conferência, principalmente as propostas da comissão brasileira da implantação de ação afirmativa no país (H tun, 2004).

Diante disto, em nossa análise, o ano de 2001 configurou-se como um marco quantitativo do destaque midiático dado às desigualdades raciais no país, 0 qual contestou o ideário da democracia racial e abriu espaço para a discussão acerca da ação afirmativa.

Já em 2003, o maior pico quantitativo das revistas e do jornal Estado de S. Paulo, há a consolidação da discussão em torno da ação afirmativa na mídia, mais especificamente sobre os sistemas de cotas raciais. Essa consolidação decorreu reativamente às leis estaduais fluminenses que implementaram cotas na U ER J e na U EN F a partir daquele ano. 0 ano de 2003 configura, portanto, o marco da consolidação da cobertura midiática sobre a ação afirmativa no Brasi l, mais especificamente o sistema de cotas.

A ascendência do enquadramento interpretativo desde 2001, que majoritariamente foi contrário ao sistema de cotas raciais, pode ser entendida como um movimento reativo aos novos elementos discursivos colocados nos quadros dominantes nacionais, a saber: 1) o reconhecimento do racismo e das desigualdades raciais no país; 2) a contestação e, consequentemente, descrédito do ideário da democracia racial, e 3) o fortalecimento político das ações afirmativas com critério racial em âmbito nacional.

A reação opositora às cotas raciais, presente no material midiático analisado, objetivou a recolocação de um conjunto de códigos nacionais por meio de grupo de intelectuais, dos quais a maioria se autointitulou como "cidadãos antirracistas" no segundo manifesto anticotas que entregaram ao Supremo Tribunal Federal em maio de 2008. 
Gráfico 2 - Frequência anual dos enquadramentos noticioso e interpretativo das revistas e jornais analisados

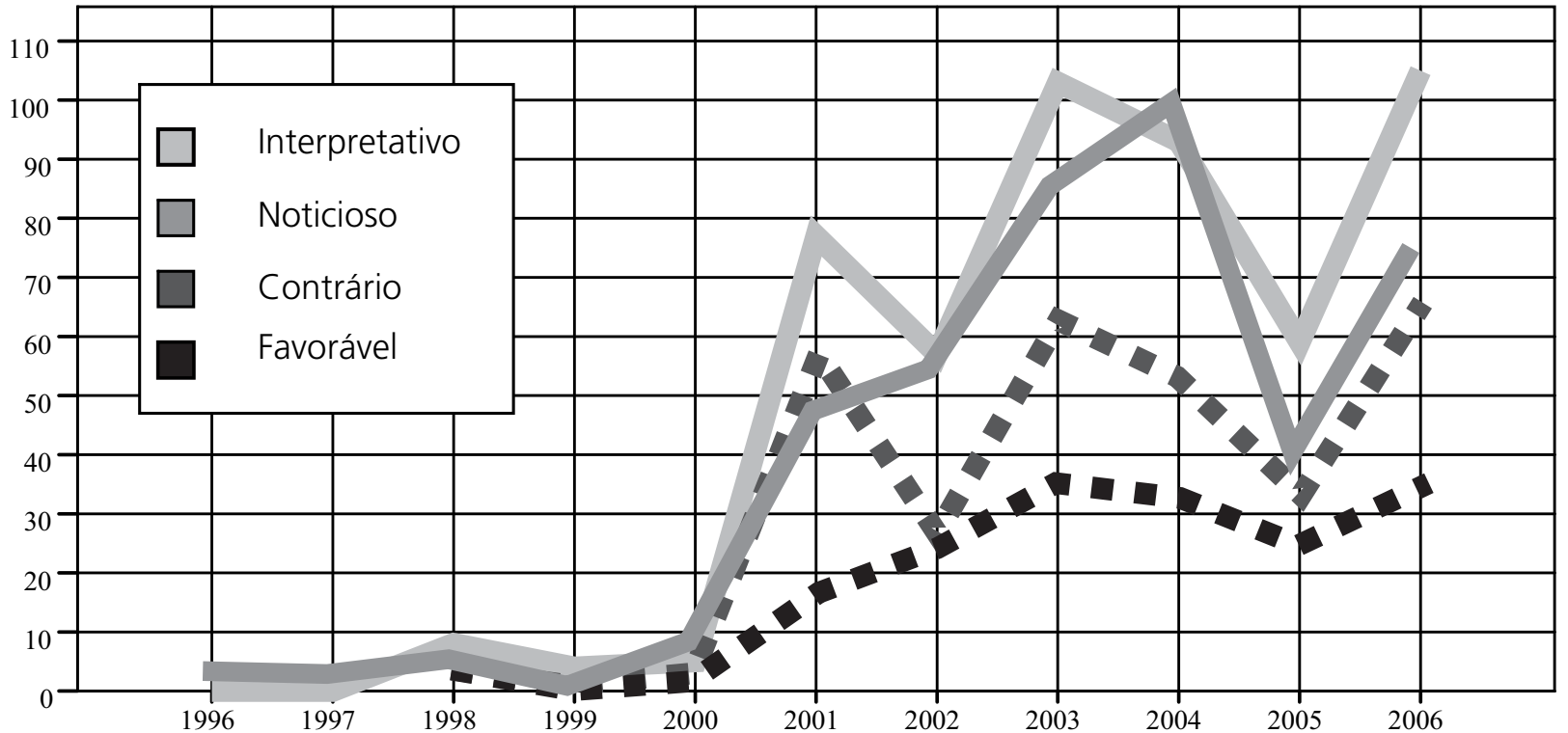

Essa reação ideológica começou a se consolidar como grupo em 2006, quando houve a elaboração e a entrega do primeiro manifesto contra a Lei de cotas e o Estatuto da I gualdade R acial entregue ao Congresso $\mathrm{N}$ acional.

0 documento com 114 assinaturas entregue quintafeira no $\mathrm{C}$ ongresso com argumentos contrários às teses de reservas de cotas raciais e ao Estatuto da Igualdade $R$ acial teve um duplo efeito: reacendeu o debate sobre os caminhos para corrigir as desigualdades sociais no País e abriu o caminho para a polarização em torno do assunto no meio acadêmico. Segundo observações do cientista político Luiz Werneck Vianna, do Instituto U niversitário de Pesquisas (luperj), o assunto é considerado muito sensível e até agora só tinham ocorrido manifestações isoladas. Essa foi a primeira vez que um grupo de intelectuais e militantes de organizações sociais se manifesta de maneira conjunta e com termos tão contundentes. 0 texto que subscrevem alerta que, em vez de eliminar o racismo, as leis propostas podem ter efeito contrário, acirrando a intolerância. Em vez de cotas, eles propõem a mel horia e a universalização efetiva dos serviços públicos, para a inclusão de todos os pobres e não só de alguns grupos. (E stado de S. Pau10, 1/ 7/2006)

Diante da análise do conteúdo dos meios de comunicação e da conjuntura política e acadêmica na- cional, é possível constatar que há em desenvolvimento um movimento ideológico que tenta reajustar os sentidos preferenciais dos códigos nacionais brasileiros e tem como objetivo principal a desarticulação política de duas categorias caras ao recente processo de reconhecimento e de denúncia do racismo brasileiro: negro e raça. Esse processo tem sido realizado por meio da veiculação de três estratégias discursivas principais. $^{7}$

A primeira estratégia foi à propagação da definição de que os negros são unicamente aqueles que se autodefinem como pretos, apresentando, inclusive, os resultados dos indicadores sociais oficiais com as categorias de raça/cor "parda e preta" desmembradas para diminuir a representatividade social e política da categoria negro, que desta forma corresponderia a algo em torno de $6 \%$ da população, por somar apenas os autodeclarados de cor preta. Essa afi rmação, veiculada midiaticamente nos últimos anos, distorce a compreensão das desigual dades sociais e raciais brasileiras até então apresentadas pelos institutos de pesquisas, pois corresponde a uma redefinição da "cor da pobreza" nacional, colocando ao centro a categoria "parda", protagonista da concepção ideal de uma nação mestiça e não segregada. D ito de outra forma, a redefinição da categoria "negro" iniciou um processo de rediscussão conceitual das desigualdades raciais no país, colocando em suspensão o crédito e a legitimidade de um conjunto histórico de pesquisas a respeito.

7 Como exemplo, pode-se observar os processos discursivos que serão descritos em publicações das três revistas analisadas: revista IstoÉ: reportagem "Qual é a sua cor?" (edição n 1648, 2006). Revista Época: reportagens "Matemática da cor" (ed. 244, 2003); "Começo errado" (ed. 244, 2003); "Será que as cotas resolvem? Pergunte a Jéssica." (ed. 409, 2006) e o editorial "Cotas num país de mestiços" (ed. 249, 2003). Revista Veja: reportagens "Cotas para quê?" (ed. 1897, 2005); "Estatuto legaliza o racismo" (ed. 1995, 2006); "Convite ao ódio racial" (ed. 1964, 2006); "Contra o mito da nação bicolor" (ed. 1969, 2006) e nas colunas "Fora, Zumbi!" (ed. 1801, 2003), "A estupidez racial" (ed. 1963, 2006), "Em honra da alma mestiça brasileira" (ed. 1972, 2006) , "Não o remédio, mas a doença" (ed. 1979, 2006), entre outros. 
A segunda estratégia, complementar a primeira, foi a ampla divulgação midiática, principalmente em $2007,{ }^{8}$ dos resultados de uma pesquisa sobre o "genoma do brasileiro" que afirmam não existir uma direta equivalência entre a composição genética, 0 fenótipo e a autodeclaração dos brasileiros em razão do alto grau de miscigenação populacional. 0 u seja, a divulgação da pesquisa, da maneira como foi realizada, tentou por via do discurso biológico (hegemonicamente apreendido como mais exato, neutro e científico do que as Ciências Sociais), desacreditar a relevância social da raça, na medida em que contesta a pertinência da identificação racial defendida pelo movimento social negro, ao mesmo tempo em que credita valor científico ao ideal nacional da mestiçagem, formulado por nossos pensadores sociais clássicos, como o próprio geneticista responsável pela pesquisa afirmou:

Vários autores, dentre os quais despontam [...] Prado, Freyre, H olanda e R ibeiro, enfatizaram a natureza híbrida da população brasileira, a partir dos ameríndios, europeus e africanos. 0 s dados que obtivemos dão respaldo científico a essa noção e acrescentam um importante detalhe: a contribuição europeia foi basicamente através de homens e a ameríndia e africana foi principalmente através das mulheres (Pena, 2000, p. 25).

Entretanto, o mesmo autor pondera acerca dos limites da biologia sobre a realidade social, dizendo que

a informação genética sobre a estrutura da população brasileira deve ser considerada apenas como um subsídio para o processo de tomada de decisões. N ão compete à genética fazer prescrições sociais. A definição sobre quem deve se beneficiar das cotas universitárias e das ações afirmativas no Brasil deverá ser resolvida na esfera política, levando em conta a história do país, o sofrimento de seus vários segmentos e análises de custo e benefício (Pena, 2006, p. 47).

A tercei ra estratégia evidencia-se na convergência das duas anteriores e apresenta a mestiçagem não apenas como o traço relevante da nacionalidade brasileira, mas como a essência nacional que está vocacionada a conter o racismo brasileiro nas relações privadas, ou seja, um racismo não institucionalizado, menos agressivo e menos segregado que em outras experiências mundiais. Portanto, as políticasafirmativas que requerem uma identificação racial são acusadas de inserir 0 "verdadeiro racismo" no Brasil, como se este aqui não vigorasse, apresentando a mestiçagem como álibi de sua inexistência.

Esses novos có digos nacionais veiculados pela mídia que realocam ao centro das discussões conceituais e políticas a mestiçagem como um fator dominante, distintivo, complicador e antirracista das nossas relações sociais parecem muito semelhantes às análises clássicas que constituíram nossa nacionalidade a partir da década 1930, entretanto, agora há o reconhecimento oficial de que as nossas desigualdades são racialmente marcadas. 0 impasse, no entanto, começa quando se reivindicam ações políticas que as equacionem e combatam suas cau sas, pois as políticas específicas com critérios raciais são veementemente tachadas de racistas e o viés racial das análises é suprimido por meio de discussões pouco ou nada propositivas.

Essa reformulação conceitual da mestiçagem brasileira pode ter encontrado brechas na própria luta do desmascaramento do ideário da democracia racial para se re-alocar como um discurso hegemônico. A final, os ataques a esse ideário tinham como intuito principal e último o reconhecimento da vigência do racismo nas relações sociais brasi lei ras, colocando a concepção da mestiçagem em um plano instrumental analítico, o que a previniu de uma crítica construtivista mais incisiva que a demonstrasse como o cerne duro, fundamental e reprodutor do dispositivo simbólico que gerencia o racismo no país.

José Jorge C arvalho (2003, p. 176) questiona a "quem" interessa esse protagonismo da mestiçagem em nossa constituição social e argumenta que 0 deslocamento dos brancos e dos negros para uma posição social intermediária caracterizada como "mestiços" pode, ao contrário do que se pensa, sustentar a ordem social racista. O sbrancos continuaram usufruindo dos privilégios advindos do racismo, ao mesmo tempo em que não são "responsabilizados" por isto, na medida em que podem se alocar na posição "neutra" da mestiçagem, a mesma posição que retira a legitimidade reivindicatória por reparação dos negros, pois estes também são concebidos como mestiços, portanto, "iguais" aos brancos.

Valter R oberto Silvério complementa que

a mestiçagem tem cumprido um papel histórico importante na manutenção racializada da elite branca, por um lado ela nega o valor da própria branquitude na alocação de posições-chave na sociedade, por ou-

8 Embora o ano de 2007 não contemple o período analisado neste artigo, é relevante destacar que a referida pesquisa foi muitas vezes citada em reportagens, artigos e cartas de leitores dos meios midiáticos brasileiros. Como exemplo, há a edição 2011, da revista Veja que estampou sua capa com os dizeres "Raça não existe". Nessa reportagem de capa, celebridades negras como Djavan, Daiane dos Santos, Milton Nascimento, Sandra de Sá, entre outros, tiveram as porcentagens de suas "origens genéticas raciais" (resultado das pesquisas de Sergio Pena) apresentadas com intuito de demonstrar que o fenótipo da pessoa não corresponde necessariamente a seu genótipo dela, pois alguns, como o Neguinho da Beija Flor, têm mais genes europeus do que africanos. O mote desta reportagem foi o fato de a comissão de vestibular da UnB distinguir dois irmãos gêmeos idênticos: um foi considerado de cor branca e outro de cor negra. 
tro, ela inibe a manifestação dos setores que sofrem os efeitos da racialização das elites. A invisibilidade do negro é decorrente de uma representação social que o "apaga", porque nós, no Brasil, não temos negros, somos todos mestiços, ao mesmo tempo, as práticas discriminatórias e racistas cotidianas são banalizadas, porque no pós- A bolição nunca tivemossegregação racial legal (Silvério, 2003, p.70).

No Brasil, inclusive no material midiático analisado, confunde-se constantemente o significado das categorias mestiçagem e miscigenação, tratando-as como sinônimos, quando, na verdade, correspondem a processos próximos, porém distintos.

A miscigenação é um conceito prioritariamente biológico que aborda a mistura genética entre populações, por meio da reprodução humana. Essa área do conhecimento tornou-se interesse político estatal no século X VIII, quando os governos notaram a necessidade de administrar os fenômenos específicos relacionados ao aumento populacional, como a taxa de natalidade, mortalidade, fecundidade etc. O u seja, a população e sua prática sexual tornaram-se um problema econômico e político, sobre o qual especificidades científicas (demografia, medicina sanitarista, etc.) se debruçaram com o intuito de administrá-lo em prol do "desenvolvimento e aperfeiçoamento" da nação. Foucault (1988, p.33) apresentou mais detal hadamente esses fatos e afirmou que as teorias racistas dos séculos seguintes encontraram nesse processo de gestão populacional seus pontos de fixação.

A mestiçagem é um conceito cultural mais abrangente que a miscigenação, pois está diretamente associada aos pilares fundamentais da constituição conceitual do Estado-nação. $\mathrm{N}$ a medida em que as prerrogativas da sua formação eram a delimitação de um único território, uma única língua e um único povo e que tais fatores não estavam dados e muitos menos eram exclusivos, a problemática das fronteiras, hibridações e misturas dos territórios, das línguas e povos tornou-se um fator social bastante relevante.

Segundo Benedict Anderson (1999, p. 164), era senso comum que a estabilidade do Estado moderno dependia que sua organização fizesse coincidir seu território com uma determinada realidade cultural preexistente, o que resultou no gerenciamento das diferenças com o intuito de uniformizá-las de acordo com o padrão dominante vigente. O u seja, "toda a ideologia de assimilação via-se baseada na ideia, por demais nacionalizante, do 'povoamento' de um território" (A nderson, 1999, p.165).

A mestiçagem, tal como conhecemos hoje, surgiu dessas demandas culturais homogeneizantes da formação das nações modernas como um processo assimilacionista que visou dar inteligibilidade específica e exclusiva a algumas nacionalidades. Processo do qual a miscigenação faz parte, como uma forma de gerir a composição racial dominante, que, no caso brasileiro, por exemplo, objetivou o branqueamento da população.

De acordo com Kabengele M unanga (2006, p. 54), somente com o fim da escravidão a formação da identidade nacional brasileira se tornou crucial para os seus pensadores, pois a partir da Abolição precisaram incluir os novos cidadãos, os ex-escravizados negros, como elementos da composição nacional do país, 0 que obviamente era um problema, em razão das teorias racistas vigentes na época.

0 que estava em jogo, nesse debate intelectual nacional, era fundamentalmente a questão de saber como transformar essa pluralidade de raças e mesclas, de culturas e valores civilizatórios tão diferentes, de identidades tão diversas, numa única coletividade de cidadãos, numa só nação e num só povo (M unanga, 2006, p. 55).

A aposta executada pela elite brasi leira fundamentou-se no que M unanga (2006, p. 121) denominou de modelo radista universalista, que se caracteriza pela negação absoluta das diferenças por meio de uma avaliação negativa delas e da sugestão de um ideal último de homogeneidade, construído por meio da miscigenação e da assimilação cultural. Portanto, o processo de mestiçagem brasileiro teve como uma das suas conseqüências "a destruição da identidade racial e étnica dos grupos dominados, ou seja, o etnocídio" (M unanga, 2006, p. 55) e a construção de uma identidade nacional homogeneamente branqueada.

0 racismo universalista se distingue do racismo diferencialista porque o último se opôs à mestiçagem, considerando- a um instrumento de supressão das diferenças que conferiam ao grupo dominante o status de superioridade e, portanto, legitimavam a dominação e a exploração das "raças inferiores". N o Brasil, onde vigorou o modelo universalista, ocorreu 0 contrário, pois, ao invés de se opor à mestiçagem, utilizou- a como um meio de neutralizar a diferença ameaçadora dos povos negros aqui presente ( $M$ unanga, 2006, p. 129).

D essa forma, entende-se por que no Brasil o discurso da integração social por meio da identidade nacional, baseada apenas nos val ores universais e integracionistas do individuo a-descritivo e pretensamente protegido pelo princípio da isonomia é fortemente colocado como a única opção aceitável de combate ao racismo. Tal alternativa em nada altera a estrutura social vigente, na qual as identidades étnicas estão hierarquicamente estabelecidas e ao mesmo tempo forjadas por uma única nacionalidade mestiça.

A "elite pensante" do Brasil foi muito coerente com a ideologia dominante e o racismo vigente ao encaminhar 0 debate em torno da identidade nacional, cujo 
elemento da mestiçagem ofereceria teoricamente 0 caminho. Se a unidade racial procurada não foi alcançada, como demonstra hoje a diversidade cromática, essa elite não deixa de recuperar essa unidade perdida recorrendo novamente à mestiçagem e ao sincretismo cultural. De fato, o que está por trás da expressão popular tantas vezes repetida: "no Brasil todo mundo é mestiço", senão a busca da unidade nacional racial e cultural? (M unanga, 2006, p. 129)

Perante esse panorama é compreensível que a forte resistência às políticas afirmativas com critério racial, por parte da mídia brasileira, utilize como uma das argumentações principais os valores presentes na elaboração da identidade nacional do país, apresentando- os como componentes essenciais do nosso processo pacífico e igualitário, porém ainda em andamento, de integração social. 0 u seja, aqueles que se opõem às políticas racialmente focadas entendem que a integração social das parcelas populacionais que ainda não foi dignamente efetuada será concretizada com a plena execução do modelo nacional vigente, por meio da universalização das políticas públicas de desenvolvimento social. Exclui-se, assim, qualquer possibilidade de que a identidade nacional brasileira seja renegociada a partir de discussões e proposições que questionam o modo pelo qual a nossa unidade mestiça foi arquitetada de maneira prejudicial aos grupos étnicos, raciais e regionais subalternos de nosso território.

Joan W. Scott (2000, p. 216) alerta que o uso indiscriminado da defesa do discurso da igualdade entre os indivíduos em contraponto às múltiplas facetas e consequências das diferenças sociais é um meio eficaz de mantê-las invisíveis e irrelevantes nas discussões políticas, estabelecendo o princípio da igualdade como "o único terreno que se pode reclamar a equidade" política e social. 0 debate midiático e intelectual sobre a ação afirmativa com critério racial no Brasil parece estar limitado a este terreno e aqueles que tentam extrapolá-lo são rechaçados, sob a acusação de quererem estabelecer um modelo identitário nacional segregacionista. Contra isto M unanga (2006, p.118) argumenta que

confundir o fato biológico da mestiçagem brasileira (a miscigenação) e o fato transcultural dos povos envolvidos nessa miscigenação com o processo de identificação e de identidade, cuja essência é fundamentalmente político-ideólogica, é cometer um erro epistemológico notável. Se, do ponto de vista biológico e sociológico, a mestiçagem e a transculturação entre povos que aqui se encontraram são fatos consumados, a identidade é um processo sempre negociado e renegociado, de acordo com os critérios ideológico-políticos e as relações de poder. 0 exemplo de alguns países ocidentais construídos segundo o modelo Estado-nação, que passavam a imagem de que havia uma unidade cultural conjugada com a unidade racial e onde ressurgem hoje os conflitos étnicos e identitários, iluminaria o processo brasileiro e, sobretudo, a ideia de que existe uma identidade mestiça. U ma tal identidade resultaria, a meu ver, das categorias objetivas da racionalidade intelectual e da retórica política daqueles que não querem enfrentar os verdadeiros problemas brasileiros (M unanga, 2006, p. 119).

O s indicadores sociais de pesquisas oficiais do país demonstram que existem profundas desigualdades nas condições de vida dos brasileiros, as quais perpassam desde o acesso a direitos básicos, como saneamento sanitário e água encanada, até o acesso aos locais de produção e negociação de poder e conhecimento, como as universidades públicas. E essas condições desiguais têm um evidente corte racial, regional e de gênero. A ssim, é incontestável que o projeto nacional brasileiro que alçou a mestiçagem como uma bandeira de integração populacional, regional e cultural não obteve êxito para aquelas pessoas marcadas pelas diferenças socialmente construídas e reproduzidas. $\mathrm{N}$ a sociedade brasileira, no cenário moderno em que as oportunidades são iguais e a isonomia dos indivíduos realmente existe, atuam como protagonistas, em sua escandalosa maioria, os homens pertencentes à parcela branca da população e residentes nas $\mathrm{R}$ egiões Sudeste e Sul.

\section{Muito além das cotas raciais: uma disputa pela definição simbólica da nação}

A grande polêmica em torno de políticas que estão especialmente preocupadas com 0 caráter racial da nossa formação nacional demonstra que esta passa por um importante momento de renegociação. A nossa análise, de aproximadamente uma década (1995-2006), dos principais jornais e revistas do país demonstrou que os mais notáveis intelectuais acadêmicos brasileiros participam ativamente, com avaliações e prognósticos, deste momento. Com as devidas proporções, parece que o período político e intelectual que vivemos se assemelha ao transcorrido no final do século XIX, início do século XX, quando a "elite pensante" do país formulava qual o tipo de sociedade seríamos.

Esta percepção leva a uma inquietante questão: onde está situada a elite intelectual acadêmica brasileira? A última avaliação trienal (2004-2006) dos programas de pós-graduação (PPG) do país realizada pela C oordenação de A perfeiçoamento de Pessoal de N ível Superior (Capes) em 2007 mostrou que ape- 
nas 82 programas dos 2.256 avaliados têm o conceito máximo (7) de excelência. Destes programas, 85,4\% estão situados na R egião Sudeste do país, dos quais $68,5 \%$ são PPGs vinculados a somente três universidades (USP, UFR J e UNICAMP). Dito de outra forma, $58,5 \%$ dos PPG s que receberam conceito de excelência máximo da $C$ apes estão situados em dois estados brasileiros ou, mais especificamente, em três universidades. As R egiões $\mathrm{N}$ orte, $\mathrm{N}$ ordeste e C entro0 este somam $2,4 \%$ dos PPG s de excelência máxima do país. ${ }^{9}$

Estes dados, além de serem mais uma comprovação de que a sociedade brasileira fal hou em seu projeto nacional de integração social, demonstram que nossa elite intelectual pensa e propõe análises sociais de lugares muito semelhantes e restritos. Fato que compromete não apenas a qualidade da produção científica nacional, mas o próprio desenvolvimento social do país, tendo em vista que a elite intelectual é um componente de peso nos debates políticos polêmicos, como o que envolve os sistemas de cotas raciais.

A oposição de maior impacto à ação afirmativa com critério racial vem da intelectualidade mais estabelecida e reconhecida do país. D os 227 signatários dos dois manifestos contrários às cotas raciais, um entregue ao Congresso em 2006 e outro entregue ao ST $\mathrm{F}$ em 2008, 47 assinaram ambos, dos quais $77 \%$ estão situados na $R$ egião Sudeste e $74 \%$ são pesqui sadores acadêmicos das principais instituições de ensino superior e de pesquisa do Brasil. ${ }^{10}$ $\mathrm{N}$ a semana em que o primeiro manifesto contrário foi divulgado, 0 Estado de $S$. Paulo publicou uma reportagem na qual definiu os seus signatários como um "conjunto de antropólogos e cientistas políticos dos mais respeitados no País." (Estado de $S$. Paulo, $\mathrm{N}$ acional, 2/7/2006)

0 grau do alcance e o impacto social desses acadêmicos podem ser estimados pelo fato de que mais de $25 \%$ deles manifestaram posicionamentos contrários às cotas raciais nos veículos midiáticos aqui analisados. U ma semana após entregarem ao C ongresso o primeiro manifesto de oposição ao Estatuto da I gualdade $\mathrm{R}$ acial e à Lei de $\mathrm{C}$ otas, 0 governo federal recuou do seu apoio ao projeto de lei que prevê o referido estatuto, propondo a substituição do critério racial pelo critério socioeconômico. A justificativa do governo, por meio do então ministro das R elações Institucionais (e ex-ministro da Educação) e publicada no jornal E stado de S. Paulo (8/7/2006) foi de como as normas do estatuto "não têm um componente social explícito e colocam diretamente a questão racial, criam um tipo de resistência e uma discussão que opõe brancos e negros". A autora da reportagem observou, por sua vez, que
0 assunto é delicado. Especialmente em um ano eleitoral, parlamentares resistem a assumir posições impopulares. M as o movimento contra a proposta cresce, porque aumenta a resistência na sociedade. C resce também o medo de que o preconceito acabe agravado. (E stado de S. Paulo, 8/ 7/ 2006)

O s poucos dias que separaram a entrega do primeiro manifesto contrário às cotas raciais ao C ongresso e a proposta do governo federal de retirar o critério racial do estatuto (da igualdade racial!), para os mais céticos, podem não significar nada mais do que uma coincidência. Entretanto, é difícil acreditar em coincidências quando observamos que os argumentos utilizados pelo governo federal são muitos semel hantes aos presentes no manifesto referido, como demonstra o trecho do documento transcrito a seguir.

A adoção de identidades raciais não deve ser imposta e regulada pelo Estado. Políticas dirigidas a grupos " raciais" estanques em nome da justiça social não eliminam o racismo e podem até mesmo produz ir 0 efeito contrário, dando respaldo legal ao conceito de raça, e possibilitando 0 acirramento do conflito e da intolerância. A verdade amplamente reconhecida é que o principal caminho para o combate à exclusão social é a construção de serviços públicos universais de qualidade nos setores de educação, saúde e previdência, em especial a criação de empregos. Essas metas só poderão ser alcançadas pelo esforço comum de cidadãos de todos os tons de pele contra privilégios odiosos que limitam 0 alcance do princípio republicano da igualdade política e jurídica. A inven ção de raças oficiais tem tudo para semear esse perigoso tipo de racismo, como demonstram exemplos históricos e contemporâneos. E ainda bloquear o caminho para a resolução real dos problemas de desigualdades (Fry et al, 2007, p. 346).

Foi também neste momento político, cerca de um mês e meio depois da entrega do primeiro manifesto contrário às cotas raciais, que 0 editorial do Folha de S. Paulo mudou seu posicionamento contrário em relação a qualquer política de cotas aplicada no processo de seleção das universidades e passou a defender tal modalidade política desde que o critério utilizado fosse o socioeconômico, mantendo o repúdio às políticas com critério racial. Vale lembrar que tal inflexão argumentativa ocorreu cerca de 20 dias depois do mesmo jornal publicar os resultados da pesquisa $D$ ataFolha, segundo a qual $65 \%$ dos brasileiros posicionaram-se favoráveis ao sistema de cotas raciais nas universidades e $87 \%$ concordaram com a afirmação de que as cotas nas universidades deveriam ser criadas para pessoas pobres, independentemente da raça. 
A mídia, a academia e o Estado brasi lei ros sabem que a discussão sobre a ação afirmativa com critério racial aborda e almeja questões muito mais profundas e abrangentes que a definição de porcentagens e tipos de critérios adotados pelos sistemas de cotas implementados no ensino superior, mercado de trabal ho e na administração pública do país. Estão cientes de que 0 que está em jogo é a possibilidade de uma redefinição dos valores, objetivos e características que compõem a sociedade em que queremos viver. Dito de outra de forma, o debate sobre a ação afirmativa com critério racial coloca em xeque 0 "pacto social" brasileiro vigente e abre espaço para a elaboração de um outro, com novas possibilidades de tratamento das diferenças sociais que aqui convivem.

Esses projetos de lei, se aplicados, darão ao Brasil uma nova autoridade moral e um novo protagonismo político no plano internacional. No plano interno, será possível a construção de uma coesão social sem a enorme sombra do silêncio dos excluídos. Para que isso ocorra, os movimentos sociais não podem confiar demasiadamente na vontade dos governantes, dado que eles são produtos do sistema de poder que naturalizou a discriminação racial. Para que eles sintam a vontade de se descolonizar, é necessário pressioná-los e mostrar-Ihes que 0 seu futuro colonial tem os dias contados. Essa pressão não pode ser obra exclusiva do movimento negro e do movimento indígena. É necessário que o M ST, os movimentos de direitos humanos, sindicais, feministas e ecológicos se juntem à luta, no entendimento de que, no momento presente, a luta pelas cotas e pela igualdade racial condensa, de modo privilegiado, as contradiç̧oes de que nascem todas as outras lutas em que estão envolvidos._(B oaventura de Sousa Santos - Folha de S. Paulo, 21/8/2006, grifo nosso)

A pertinência da aprovação do estatuto é uma questão política e moral. E sse processo não pode ser visto de forma dissociada do projeto do $B$ rasil enquanto nação, e dos correspondentes modelos desejáveis de sociedade. De fato, muitos vociferam que tal modelo deveria banir a raça do horizonte. Porém seria silenciando sobre as evidentes assimetrias raciais causadas pelo racismo à brasileira que tal desiderato seria alcançado? Tornando naturais tais disparidades, violências e injustiças - resultado prático do modelo brasileiro de relações raciais - é que chegaremos a viver em um país melhor? (Flávio Gomes e M arcelo Paixão - Folha de S. Paulo, 29/4/2006, grifo nosso)

A historiografia já mostrou que a Lei Áurea apenas reconheceu formalmente uma abolição que de fato já tinha acontecido. Da mesma forma, votando a Lei de Cotas e o Estatuto da Igualdade $R$ acial, senadores e deputados reconhecerão uma ação afirmativa que já acontece em quase 30 universidades públicas do Bra- sil. A elite mobiliza uma única e cínica argumentação: 0 racismo seria produzido pelas cotas. $N$ o meio desse lixo conservador, uma questão merece ser aprofundada: 0 futuro do projeto de nação. (A ntonio N egri e Giuseppe Cocco - Folha de S. Paulo, 01/09/2006, grifo nosso)

A aprovação do estatuto significará uma alteração radical nas bases universalistas da $\mathrm{C}$ onstituição brasileira, uma vez que esse documento legal concebe a "raça" como figura jurídica de direitos a ser contemplada por políticas públicas. U ma intervenção legal dessa natureza deve supor, em primeiro lugar, a existência de uma sociedade na qual os indivíduos se autoidentifiquem através do pertencimento racial. 0 ra, se esse não é o caso da sociedade brasileira, que tem evitado a rigidez de classificações étnico-raciais, pode-se afirmar que 0 estatuto é um instrumento legal que pretende reinventar, nos termos da raça, a nação brasileira. (M onica Grin - E stado de S. Paulo, 30/ 04/2006, grifo nosso)

O s críticos da política de cotas raciais estão querendo alertar a sociedade brasileira de que se desenrola uma operação política e ideológica para transformar nossa sociedade em uma sociedade dividida "legalmente" em brancos e negros e afirmando ser preciso dar às políticas públicas a natureza universal ista que devem ter. (Y vonne M aggie - Folha de S. Paulo, 11/10/2006, grifo nosso)

Em nossa análise dos enquadramentos midiáticos argumentativo e de prognósticos, foi possível constatar que aqueles que se posicionam contrariamente à ação afirmativa com critério racial mantêm, em última instância, uma postura conservadora em relação aos princípios universalistas fundantes de nossa formação nacional, pois acreditam fortemente que a 'ideologia meritocrática' que os orientam garante 0 desenvolvimento democrático de nossa sociedade.

0 artigo 50 da C onstituição está prestes a ser derrubado pelo Estatuto da Igualdade R acial. A provado sem discussão pelo Senado, o projeto tramita na C âmara em regime de prioridade. Se entrar em vigor, representará uma mudança essencial nos fundamentos políticos e jurídicos que sustentam a nação brasileira. É, nem mais nem menos, uma nova Constituição. 0 estatuto cancela o princípio republicano de cidadania. [...] A nação deixará de ser um contrato entre indivíduos para se tornar uma confederação de "raças". [...] D istraídos, os senadores revogaram a Constituição. Seria demais solicitar aos de putados que lessem o texto do estatuto antes de mudar a naturez a política da R epública? (D emetrio M agnoli - Folha de S. Paulo, 12/ 01/2006, grifo nosso)

Pergunta-se então: a quem serve a nova sociedade que 0 estatuto quer edificar? U m Brasil dividido em "raças" promoveria justiça para todos os excluídos das oportunidades econômicas, políticas, sociais e culturais? Se- 
ria a promoção da "raça" o melhor antídoto contra o racismo e seus efeitos? [...] Por fim, caberá aos nossos representantes no $\mathrm{C}$ ongresso a responsável decisão sobre o modelo de sociedade que se quer adotar: uma onde o prinápio da igualdade dos indivíduos fundamente o $E$ stado de D ireito; ou outra na qual a "raça" se torne um princípio absoluto a pautar as ações do governo e as formas de interação dos indivíduos. (M onica Grin - E stado de S. Paulo, 30/4/2006, grifo nosso)

Como vimos, o mesmo conservadorismo presente nos acadêmi cos contrários às cotas raciais é requerido, por eles, aos congressistas, na tentativa de barrar os projetos de lei em tramitação nas casas legislativas. De maneira semel hante, todas os veículos de mídia aqui analisados defenderam veementemente, por meio dos seus editoriais, a permanência do ideário meritocrático, como único escopo político possível para pensar a sociedade brasileira. Postura que provavel mente converge com a opinião dos seus públicos-alvo, ou seja, os seus leitores, tendo em vista que o perfil deles corresponde a uma el ite econômica (mais de 60\% são de classe A e B), regional (mais de $55 \%$ situam-se no Sudeste) e acadêmica (quase $40 \%$ completaram 0 ensino superior), bastante privilegiada e bem distante da média da população brasileira. Portanto, não é espantoso que tais meios de comunicação mantenham de maneira tão evidente o posicionamento contrário a políticas que questionam e propõem mudanças na estrutura social vigente, uma que a maioria dos seus clientes goza o que de melhor e mais privilegiado existe nela.

0 que assusta, porém, é perceber que essas fatias restritas e elitizadas detêm quase um monopólio da 'produção do saber legítimo' sobre nossa sociedade. Determinam que o racismo institucional no Brasil não existe e este passa a ser novamente objeto de dúvida. A firmam que a identificação racial não compõe o imaginário social dos brasileirose o processo secular de racialização aqui vigente é abafado e suplantado pelo crivo socioeconômico. Fixam que a população negra é formada apenas pelas pessoas autodeclaradas de cor preta e toda uma luta política histórica do movimento social negro é ignorada. Enfim, na última década, desde que a ação afirmativa para a população negra foi proposta no país, uma série de afirmações contestáveis foi publicada e propagada nos meios mi- diáticos, acadêmicos e estatais e aceita como verdadeiros axiomas.

Boaventura de Sousa Santos argumenta que, no Brasil,

se naturalizou um sistema de poder, até hoje em vigor, que, sem contradição aparente, afirma a liberdade e a igualdade e pratica a opressão e a desigualdade. A ssentes nesse sistema de poder, os ideais republicanos de democracia e igualdade constituem hipocrisia sistêmica. Só quem pertence à raça dominante tem 0 direito (e a arrogância) de dizer que a raça não existe ou que a identidade étnica é uma invenção. 0 máximo de consciência possível dessa democracia hipócrita é diluir a discriminação racial na discriminação social. (Boaventura de Sousa Santos - Folha de S. Paulo, $21 / 8 / 2006)$

A ação afirmativa surgiu no Brasil como uma possibilidade política de transformar esse sistema que impede que determinadas pessoas tenham acesso a locais e cargos de poder, em razão de estarem alocadas em posições ou grupos concebidos socialmente como inferiores. A ação afirmativa é uma atitude política que resulta à compreensão analítica de que 0 acesso ao poder e a completa cidadania dos indivíduos foram cerceados da maioria deles, exatamente porque, na prática, estes não são reconhecidos e tratados como tais. O u seja, os processos simbólicos resultantes do racismo, do sexismo, do regionalismo, da homofobia, etc. despiram a individualidade daqueles enquadrados como desviantes do padrão eurocentrado e consolidaram- nos coletivamente.

D iante disto entendemos por que o foco das políticas afirmativas (os grupos e não os indivíduos) é incessantemente acusado de paradoxal. Entretanto, não é a ação afirmativa que é paradoxal, mas a própria sociedade que trata convenientemente alguns como indivíduos e outros como coletivos marginalizados. Portanto, se 0 atual processo de re-definição do Estado nacional brasileiro ignorar esse paradoxo, insistindo apenas em políticas nomeadas universal istas, porque estas respeitariam a isonomia dos indivíduos, sem dúvida, persistiremos em paradigmas políticos que jamais alcançarão seus objetivos idealizados e prometidos, ou seja, o tratamento igual entre os diferentes. 


\section{Referências Bibliográficas}

AN DER SON , Benedict. As promessas do Estado-nação para o início do século. In: HELLER Agnes et al. A crise dos paradigmas em $C$ iências Sociais e os desafios para o século X X I. R io de Janeiro: C ontraponto, 1999.

BER N AR DIN O, Joaze. Levando a raça a sério: ação afirmativa e correto reconhecimento. In: ; GALDI-

N O, D aniela. (O rgs.). L evando a raça a sério: ação afirmativa e universidade. $R$ io de Janeiro: DP\&A, 2004.

CAR VA LHO, José Jorge. A ções afirmativas como resposta ao racismo acadêmico. Teoria e Pesquisa, n. 42/43, p. 303340, 2003.

. A sações afirmativas para negros na pós- graduação, nas bol sas de pesquisa e nos concursos para professo res universitários como resposta ao racismo acadêmico. In: SIL VA, P. B. G.; SILVÉR IO , V. R . (O rgs.). E ducação e ações afirmativas: entre a injustiça simbólica e a injustiça econômica. Brasília: Inep, 2003.

CO STA, Sérgio. A construção sociológica da raça no Brasil. E studos afro-asiáticos. v. 24, n.1, p. 35-61, 2002.

FOU CAU LT, M. A história da sexualidade I: a vontade de saber. R io de Janeiro: Graal, 1988.

. M icrofísica do poder. R io de Janeiro: Graal, 1981.

FRY, Peter et al. D ivisões perigosas: políticas raciais no Brasil contemporâneo. R io de Janeiro: Civilização Brasileira, 2007.

GUIM AR ÃES, Antonio Sérgio Alfredo. R adismo e antiracismo no B rasil. 2a ed. São Paulo: Fundação de Apoio à U niversidade de São Paulo/ Ed. 34, 2005 [1999].

. C lasses, raças e democracia. São Paulo: Fundação de A poio à U niversidade de São Paulo/Ed. 34, 2002. Como trabalhar com "raça" em sociologia. E ducação e Pesquisa, v. 29, n. 1, p. 93-107, 2003.

HEN R IQ U ES, R icardo. D esigualdade racial no B rasil: evoluções das condições de vida na década de 90. Texto para discussão, no 807. R io de Janeiro: Instituto de Pesquisa Econômica A plicada, 2001.

H T U N , M ala. From "racial democracy" to affirmative action: changing state policy on race in B razil. $L$ atin $A$ merican R esearch R eview, v. 39, n. 1, p. 60-89, 2004.

KA M EL, Ali. N ão somos racistas: uma reação aos que querem nos transformar numa nação bicolor. $\mathrm{R}$ io de Janeiro: N ova Fronteira, 2006.

LEAL, Plínio M arcos Volponi. Jornalismo político brasileiro e a análise de enquadramento noticioso. In: CONGR ESSO DA ASSO CIAÇÃO BR ASILEIR A DE PESQUISADORES EM COMUNICAÇÃO E POLÍTICA, 2, 2007, Belo Horizonte, MG. Disponível em: <http://www.fafich.ufmg. br/compolitica/anais2007/sc_jp-plinio.pdf>. Acesso em: 30.mar.2009.

MISKOLCI, R ichard. Do desvio às diferenças. Teoria \& Pesquisa, v. 1, n. 47, p. 9-42, 2005.

A hora da eugenia: raça, gênero e nação na A mérica Latina. C adernos de Saúde Pública, v. 22, n. 1, p. 2006. U ma brasileira: a outra história de Julia Mann.
C adernos Pagu, n. 20, p. 157-176, 2003.

M U N A N GA, K abengele. Políticas de ação afirmativa em benefício da população negra no Brasil: um ponto de vista em defesa de cotas. In: SI LVA, P. B. G.; SI LVÉR IO , V. R. (O rgs. ). E ducação e ações afirmativas: entre a injustiça simbólica e a injustiça econômica. Braślia: Inep, 2003. . 0 anti-racismo no Brasil. In: (O rg.). Estratégias e políticas de combate à discriminação racial. São Paulo: Edusp, 1996.

- R ediscutindo a mestiçagem no B rasil: identidade nacional versus identidade negra. Petrópolis: Vozes, 2006. PEN A, Sérgio D. J. et al. R etrato molecular do Brasil. C iência H oje, v.17, n.159, p. 16-25, 2000.

; BORTOLIN I, Maria Cátira. Pode a genética definir quem deve se beneficiar das cotas universitárias e demais ações afi rmativas? E studos A vançados, v 18, n. 50, p. 31-50, 2004.

; BIR CH A L, Telma S. Inexistência biológica versus a existência social de raças humanas: pode a ciência instruir o etos social? R evista U SP, n. 68, p. 10-21, 2006. POR TO , M auro Pereira. A mídia brasileira e a eleição presidencial de 2000 nos EU A : a cobertura do jornal Fol ha de S. Paulo. C adernos do C E A M , ano II, n. 6, p. 11-32, 2001.

A pesquisa sobre a recepção e os efeitos da mídia: propondo um enfoque integrado. In: CONGR ESSO BR ASILEIRO DE CIÊNCIAS DA COMUNICAÇÃO (IN TER COM ), 26, 2003, Belo Horizonte, MG. XXV I Intercom: Caderno de resumos. B elo Horizonte: U niversidade Federal de M inas Gerais, 2003, p. 51.

Enquadramentos da mídia e política. In: RU -

BIM , Antonio Albino (O rg.). C omunicação e Política: conceitose abordagens. Salvador: EdU FBa, 2004.

N ovos apresentadores ou novo jornalismo? 0 Jornal $\mathrm{N}$ acional antes e depois da saída de Cid Moreira. C omunicação e E spaço Público, v. 5, n. 1/2, p. 9-31, 2002. RODR IGUES, Tatiane Cosentino. Movimento negro, raça e política educacional. In: R EUNIÃO AN UAL DA ASSO CIAÇÃO NACIO NAL DE PÓS-GR ADUAÇÃO E PESQUISA EM EDUCAÇÃO, 28, 2005, Caxambu, MG. Disponível em: <www.anped.org.br/reunioes/28/ textos/gt21/gt211249int.rtf>. A cesso em: 30.mar.2009. SC OTT, Joan W. 0 enigma da igualdade. E studos F eministas, v. 13, n. 1, p.11-30, 2005.

. Igualdade versus diferença: os usos da teoria pósestruturalista. D ebate Feminista (C idadania e Feminismo), no especial, p. 207-218, 2000.

SCHEU FELE, Dietram A. Framing as a theory of media effects. Journal of Communication, v. 49, n. 1, p. 103-122, 1999.

SILVÉR IO, Valter R. O papel das ações afirmativas em contextos racializados: algumas anotações sobre o debate brasileiro. In: SILVA, P. B. G.; SILVÉR IO, V. R. (O rgs.). E ducação e ações afirmativas: entre a injustiça simbólica e a injustiça econômica. Brasília: Inep, 2003. 
N egros em movimento: a construção da autonomia pela afirmação dos direitos. In: BER N A R DIN 0 , Joaze; GA LDIN O, D aniela. (O rgs.). L evando a raça a sério: ação afirmativa e universidade. $R$ io de Janeiro: DP\&A, 2004.
ST EPAN, N ancy Lewis. R aça e gênero: o papel da analogia na ciência. In: HOLLAN DA, Heloísa Buarque de (O rg.). Tendências e impasses: o feminismo como crítica da cultura. R io de Janeiro: R occo, 1994.

\title{
Affirmative action and race in contemporary Brazil: a debate on the nation's symbolic redefinition
}

\begin{abstract}
The article analyzed the impact of A ffirmative Action with racial criterion in Brazilian media (magazines V eja, Istoé and É poca and new spapers F olha de S. Paulo and 0 E stado de S. Paulo) through the framing analysis for the period between 1995 and 2006 concerning the consolidation of the theme within the state. The analysis emphasized the interpretative framings of "Position", which corresponds to the publications which presented assessments of the racial quota system; of "A rguments", which noted the argumentative structures that sustained the valuations; and of "Prognosis", which explored the alternative or complementary proposals to the mentioned system. The main conclusion refers to the decrease of complaints about racial inequalities in B razil since 2005, accompanied by a dramatic increase of reports and articles detrimental to the advancement of Affirmative Action with racial criterion in the country.
\end{abstract}

Key words: racial relations; affirmative action; state; nation; framing.

\section{Acción afirmativa y raza en Brasil contemporáneo: un debate sobre la redefinición simbólica de la Nación}

\begin{abstract}
Resumen
El artículo analizó la repercusión de la Acción A firmativa con criterio racial en los medios de comunicación impresos brasileños (revistas V eja, É poca e I stoé y los periódicos F olha de São Paulo y E stado de São Paulo) por medio del análisis de encuadramiento, durante el período de 1995 a 2006, referente a la consolidación de la temática en el ámbito estatal. El análisis enfatizó los encuadramientos interpretativos de "Posicionamiento", que corresponde a las publicaciones que presentaron evaluaciones sobre el sistema de cuotas raciales; de "A rgumentación", que observó las construcciones argumentativas que sostuvieron a las referidas evaluaciones; y de "Prognóstico", que exploró las propuestas alternativas o complementarias al sistema citado. La principal conclusión se refiere a la disminución de las denuncias sobre las desigualdades raciales brasileñas a partir de 2005, acompañadas de un intenso aumento de reportajes y artículos desfavorables al avance de la Acción A firmativa con criterio racial en el país.
\end{abstract}

Palabras clave: relaciones raciales; Acción Afirmativa; Estado; nación; encuadramiento de los medios de comunicación impresos.

Data de recebimento do artigo: 30-03-2009

D ata de aprovação do artigo: 25-09-2009 
